\title{
Biowaiver Monographs for Immediate-Release Solid Oral Dosage Forms: Codeine Phosphate
}

\author{
ARIK DAHAN, ${ }^{1}$ OMRI WOLK, ${ }^{1}$ MORAN ZUR, ${ }^{1}$ GORDON L. AMIDON, ${ }^{2}$ BERTIL ABRAHAMSSON, ${ }^{3}$ RODRIGO CRISTOFOLETTI, \\ D. W. GROOT, ${ }^{5}$ SABINE KOPP, ${ }^{6}$ PETER LANGGUTH, ${ }^{7}$ JAMES E. POLLI, ${ }^{8}$ VINOD P. SHAH, ${ }^{9}$ JENNIFER B. DRESSMAN ${ }^{10}$ \\ ${ }^{1}$ Department of Clinical Pharmacology, School of Pharmacy, Faculty of Health Sciences, Ben-Gurion University of the Negev, \\ Beer-Sheva 84105, Israel \\ ${ }^{2}$ Department of Pharmaceutical Sciences, College of Pharmacy, University of Michigan, Ann Arbor, Michigan \\ ${ }^{3}$ Pharmaceutical Development, AstraZeneca R\&D, Mölndal, Sweden \\ ${ }^{4}$ Brazilian Health Surveillance Agency (Anvisa), Division of Bioequivalence, Brasilia, Brazil \\ ${ }^{5}$ RIVM (National Institute for Public Health and the Environment), Bilthoven, The Netherlands \\ ${ }^{6}$ World Health Organization, Geneva, Switzerland \\ ${ }^{7}$ Institute of Pharmacy, Biopharmaceutics and Pharmaceutical Technology, Johannes Gutenberg-University, Mainz, Germany \\ ${ }^{8}$ Department of Pharmaceutical Sciences, School of Pharmacy, University of Maryland, Baltimore, Maryland \\ ${ }^{9}$ International Pharmaceutical Federation (FIP), The Hague, The Netherlands \\ ${ }^{10}$ Institute of Pharmaceutical Technology, Johann Wolfgang Goethe University, Frankfurt am Main, Germany
}

Received 19 February 2014; revised 23 March 2014; accepted 31 March 2014

Published online 1 May 2014 in Wiley Online Library (wileyonlinelibrary.com). DOI 10.1002/jps.23977

\begin{abstract}
The present monograph reviews data relevant to applying the biowaiver procedure for the approval of immediate-release multisource solid dosage forms containing codeine phosphate. Both biopharmaceutical and clinical data of codeine were assessed. Solubility studies revealed that codeine meets the "highly soluble" criteria according to World Health Organization (WHO), the European Medicines Agency (EMA), and the United States Food and Drug Administration (US FDA). Codeine's fraction of dose absorbed in humans was reported to be high ( $>90 \%$ ) based on cumulative urinary excretion of drug and drug-related material following oral administration. The permeability of codeine was also assessed to be high in both Caco-2 monolayers and rat intestinal perfusion studies. The main risks associated with codeine, that is, toxicity (attributed to CYP2D6 polymorphism) and its abuse potential, are present irrespective of the dosage form, and do not need to be taken into account for bioequivalence (BE) considerations. Taken together, codeine is a class 1 drug with manageable risk and is a good candidate for waiver of in vivo BE studies. (c) 2014 Wiley Periodicals, Inc. and the American Pharmacists Association J Pharm Sci 103:1592-1600, 2014
\end{abstract}

Keywords: absorption; bioavailability; bioequivalence; biopharmaceutics classification system (BCS); codeine phosphate; permeability; dissolution; solubility

\section{INTRODUCTION}

The present biowaiver monograph addresses the active pharmaceutical ingredient (API) codeine phosphate. This monograph is a part of the biowaiver monograph series by the International Pharmaceutical Federation (FIP) that currently contains over 40 monographs (http://www.fip.org/bcs). The purpose of this series is to assess whether in vivo pharmacokinetic bioequivalence (BE) studies can be safely waived in favor of in vitro dissolution studies for the approval of new immediate-release (IR) solid oral dosage forms of a given API. Each monograph is based on a comprehensive literature review, which forms the basis of the risk-benefit analysis of applying a biowaiver-based approval to new or extensively revised formulations of the given API. Some of the properties discussed include the solubility of the API, pharmacokinetics and permeability data, the therapeutic use and therapeutic index, data on excipient interactions, and any problems that have been

Correspondence to: Jennifer B. Dressman (Telephone: +49-69-7982-9680 Fax: +49-69-7982-9724; E-mail: dressman@em.uni-frankfurt.de)

Journal of Pharmaceutical Sciences, Vol. 103, 1592-1600 (2014)

(C) 2014 Wiley Periodicals, Inc. and the American Pharmacists Association reported with bioavailability (BA) and/or BE. On the basis of these properties, a risk-benefit analysis is performed and a decision to recommend or advise against biowaivers for the given API is made.

\section{GENERAL CHARACTERISTICS}

Scope

This monograph refers exclusively to the phosphate salt of codeine. The analysis is relevant primarily for oral formulations in which codeine phosphate is the sole active ingredient; it may also be applied for combination products containing codeine phosphate. However, for combination products, the other APIs and their potential interaction with codeine phosphate should be analyzed as well. Modified/extended release formulations are also out of the scope of this analysis.

\section{Name}

Codeine is an opioid derived from the unripe seed capsules of the poppy plant (Papaver somniferum), and it has a similar structure to morphine, with a methyl substitution on the 


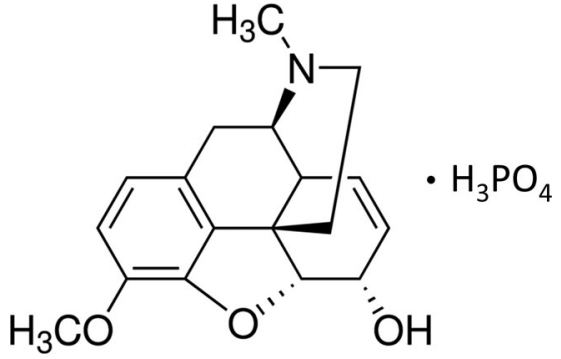

Figure 1. Molecular structure of codeine.

phenolic hydroxyl group. ${ }^{1}$ The chemical description of the phosphate salt form is 7,8-didehydro-4,5 alpha-epoxy-3-methoxy17-methylmorphinan-6 alpha-ol phosphate (1:1) and has the molecular formula of $\mathrm{C}_{18} \mathrm{H}_{21} \mathrm{NO}_{3} \cdot \mathrm{H}_{3} \mathrm{PO}_{4} \cdot 1 / 2 \mathrm{H}_{2} \mathrm{O}$. Codeine has one chiral center. Its molecular weight is $406.4 \mathrm{~g} / \mathrm{mol}$ and its melting point is $155^{\circ} \mathrm{C}$ (Merck Index). The structure of codeine phosphate is given in Figure 1.

\section{Therapeutic Indication and Dose}

Codeine phosphate demonstrated antitussive activity in several clinical trials performed between 1966 and $1984 .^{2} \mathrm{Al}-$ though this effect was observed in patients suffering from chronic cough as a result of diseases such as bronchitis or chronic obstructive pulmonary disease, the prescription of codeine for acute cough has become a common practice over the years. However, more recent studies failed to demonstrate any antitussive effect of this drug when compared with placebo. ${ }^{3,4}$ Therefore, codeine phosphate is currently recommended by the American College of Chest Physician (ACCP) for the alleviation of chronic but not acute cough. ${ }^{5}$ Reports in the literature on the daily dose of codeine required for cough suppression ranges between 7.5 and $60 \mathrm{mg}^{5}$

Codeine is also indicated for the relief of mild to moderately severe pain. The analgesic properties of codeine stem from its conversion to morphine and morphine-6-glucuronide because codeine's affinity for $\mu$-opioid receptors is 200 -fold weaker than that of morphine. ${ }^{6,7}$ Codeine has one chiral center, and some data suggest stereospecific analgesic (but not antitussive) effect of the $d$ - and $l$-isomers. ${ }^{8}$ Yet, to the best of our knowledge, all marketed products include the racemic mixture of codeine. The recommended initial dose for pain relief is 15-30 mg every $6 \mathrm{~h}$. This dose can be increased in increments of 15-30 mg per day up to a total daily dose of $600 \mathrm{mg} .^{9}$

\section{Therapeutic Index and Toxicity}

The main toxic effects of codeine are central nervous system (CNS) and respiratory depression, both of which stem from the conversion of codeine to morphine by CYP2D6..$^{10,11}$

Codeine is not listed on the official list of narrow therapeutic index (NTI) drugs published by the National Institute of Health Sciences in Japan (http://www.nihs.go.jp) or in the NTI drug list of the US FDA published in 1988 (http://ecapps.health.state.pa.us). However, it is difficult to determine the therapeutic index of codeine, as both the effective and lethal dose are highly dependent on the genetic polymorphism of CYP2D6: the alleles CYP2D6 may be characterized as having normal function, reduced function, or nonfunctional based on the expected activity level of the enzyme for which they encode. Each functional group is assigned an activity value ranging from 0 to 1.0 (e.g., 0 for nonfunctional, 0.5 for reduced function, and 1.0 for fully functional). These values are used to assign a total activity score for each genotype; the majority of patients have an activity score of 1.0-2.0 and present an extended metabolizers (EM) phenotype. Roughly $2 \%$ of patients have an activity score greater than 2.0 and are ultrarapid metabolizer (UM), whereas patients with activity scores of 0.5 and 0 are intermediate metabolizers and poor metabolizers, respectively. ${ }^{11,12}$ This polymorphism has significant influence on the efficacy and toxicity. ${ }^{13}$ Indeed, cases of toxicity on the one hand and lack of therapeutic effect on the other hand have been documented, even when the standard dose was administered..$^{10,14,14-16}$ As a result, the expected CYP2D6 phenotype of the individual patient, as well as the specific population, must be taken into account whenever codeine administration is considered. ${ }^{11}$

\section{METHODS}

\section{Literature Analysis}

Literature data were obtained from PubMed, Micromedex, the Merck Index, and Goodman and Gilman's "The pharmacological basis of therapeutics" $\left(11^{\text {th }}\right.$ edition). The keywords used for searching were: codeine, intestinal absorption, $\mathrm{BA}, \mathrm{BE}, \log P$, solubility, permeability, pharmacokinetics, polymorphism, 2D6, mass balance, metabolism, and radiolabeled studies.

\section{Solubility Experiments}

For the solubility experiments, a standard shake-flask method was applied using three different aqueous media with $\mathrm{pH}$ values of 1.0 (maleate buffer), 4.5 (acetate buffer), and 7.5 (phosphate buffer) at $37^{\circ} \mathrm{C}$. Solubility studies were performed at the Department of Clinical Pharmacology, Ben-Gurion University of the Negev, Beer-Sheva, Israel, using analytical grade codeine phosphate (generously donated by Rekah Pharmaceutical Industry Ltd., Holon, Israel). The establishment of equilibrium was confirmed by comparison of 24- and 48-h samples. The $\mathrm{pH}$ was measured both before and after the experiment, to assure that the solubility was indeed registered at the correct $\mathrm{pH}$. Drug levels in the samples were analyzed by ultraperformance liquid chromatography (UPLC), using a previously described method. ${ }^{17}$ Three replicates were carried out in each $\mathrm{pH}$ condition.

\section{Permeability Experiments}

The effective permeability coefficient $\left(P_{\text {eff }}\right)$ of codeine versus metoprolol was determined in situ using the single-pass rat intestinal perfusion model. The experimental procedure followed previous reports. ${ }^{18-20}$

To account for the complexity of the whole of the small intestine, permeability was determined in three different $10-\mathrm{cm}$ segments: a proximal jejunal segment, mid-small intestinal segment, and a distal ileal segment. ${ }^{21-23}$ Briefly, each intestinal segment was cannulated on two ends, and was perfused with the corresponding phosphate buffer containing codeine and metoprolol. The concentrations of codeine and metoprolol in the perfusion buffers were 240 and $400 \mu \mathrm{g} / \mathrm{mL}$, respectively, to represent the maximal dose of the drugs $(60$ and $100 \mathrm{mg}$, respectively) in $250 \mathrm{~mL}$. The physiological $\mathrm{pH}$ of the perfused small intestinal region dictated the $\mathrm{pH}$ throughout the experiment: (1) proximal jejunum, $\mathrm{pH} 6.5$; (2) middle small intestine, 
$\mathrm{pH} 7.0$; and (3) distal ileum, $\mathrm{pH} 7.5 .^{24}$ Steady-state conditions were ensured by conducting an initial 60-min perfusion, followed by additional $60 \mathrm{~min}$ with samples taken every $10 \mathrm{~min}$ and immediate UPLC analysis. ${ }^{17}$ At the end of the experiment, the length of each perfused intestinal segment was accurately measured. ${ }^{25,26}$ Additionally, the $\mathrm{pH}$ of the collected samples was measured to verify that there was no $\mathrm{pH}$ change during the perfusion.

The $P_{\text {eff }}(\mathrm{cm} / \mathrm{s})$ through the rat gut wall was determined according to the following equation:

$$
P_{\mathrm{eff}}=\frac{-Q \ln \left(C_{\mathrm{out}}^{\prime} / C_{\mathrm{in}}^{\prime}\right)}{2 \pi R L}
$$

where $Q$ is the perfusion buffer flow rate $(0.2 \mathrm{~mL} / \mathrm{min}), C^{\prime}{ }_{\text {out }} / C^{\prime}$ in is the ratio of the outlet and the inlet concentration of drug that has been adjusted for water transport, ${ }^{27-29} R$ is the radius of the intestinal segment (set to $0.2 \mathrm{~cm}$ ), and $L$ is the length of the perfused intestinal segment.

\section{CHEMICAL PROPERTIES}

\section{Polymorphism}

No information on whether codeine exhibits polymorphism in the solid state could be identified in the literature. One should not confuse this term with the genetic polymorphism of the metabolic enzyme CYP2D6, which is involved with the metabolism of codeine and is discussed hereinafter.

\section{Dosage Form Strengths and Dose}

Oral dosage forms that contain codeine phosphate as the only active ingredient exist in several countries, with dosage strength that ranges between 15 and $60 \mathrm{mg}$.

The WHO (http://www.who.int), and Canadian guideline for safe and effective use of opioids for chronic noncancer pain ${ }^{9}$ register a maximal dose of $30 \mathrm{mg}$ for codeine phosphate, although the Clinical Pharmacogenetics Implementation Consortium (CPIC) guidelines specify a maximal dose of up to $60 \mathrm{mg}$ every 4 h. ${ }^{11}$

\section{Solubility}

The Merck Index and Martindale report codeine phosphate as being "freely soluble in water." Because the solubility data for codeine phosphate available in the literature do not cover the $\mathrm{pH}$ range of $1.0-7.5$ at $37^{\circ} \mathrm{C}$, as required by the FDA guidelines, ${ }^{30}$ additional solubility investigations were performed to classify its solubility properties according to the Biopharmaceutics Classification System (BCS).

According to the FDA, a drug substance is considered highly soluble when the highest dose strength is soluble in $250 \mathrm{~mL}$ or less of aqueous media over the $\mathrm{pH}$ range of $1-7.5$. This can be demonstrated through the calculation of the dose number $\left(D_{0}\right)$ according to the equation:

$$
D_{0}=M / V_{0} / C_{\mathrm{S}}
$$

where $M$ is the highest dose strength, $V_{0}$ is set at $250 \mathrm{~mL}$, and $C_{\mathrm{S}}$ is the equilibrium solubility of the drug. A $D_{0}$ value of $\leq 1$ means that the highest dose strength is soluble in $250 \mathrm{~mL}$ of the investigated aqueous media, and hence indicates "high solubility." For codeine phosphate, with highest dose strength of
Table 1. Physiochemical Properties of Codeine Phosphate

\begin{tabular}{lc}
\hline Dosage Range & Up to $60 \mathrm{mg}$ \\
Solubility & More than $120 \mathrm{mg} / \mathrm{mL}$ throughout \\
& the $\mathrm{pH}$ range of $1-7.5$ \\
$\log P$ & 1.1 \\
$\mathrm{p} K \mathrm{a}$ & 8.2 \\
Ionization state & Base \\
$\log D_{6.5}$ & 0.25 \\
$\log D_{7.5}$ & 0.6 \\
\hline
\end{tabular}

$60 \mathrm{mg}$, the minimal solubility that would lead to the "high solubility" classification is $0.24 \mathrm{mg} / \mathrm{mL}$. We found that the solubility of codeine exceeded $120 \mathrm{mg} / \mathrm{mL}$ throughout the $\mathrm{pH}$ range of 1 7.5 , which means that the $D_{0}$ of codeine is lower than 0.002 , unequivocally indicating a BCS high-solubility classification.

\section{Partition Coefficient}

Codeine is a moderately lipophilic compound and has a $\log P$ value of 1.1 (octanol-water). ${ }^{31}$ At the small intestinal $\mathrm{pH}, 6.5$ 7.5 , codeine has positive $\log D$ values, ranging from 0.25 (log $\left.D_{6.5}\right)$ to $0.6\left(\log D_{7.5}\right)($ Table 1$)$.

\section{pKa}

Codeine is a weak base and has a $\mathrm{pKa}$ value of $8.2 .^{32}$

\section{PHARMACOKINETIC PROPERTIES}

\section{Absorption and BA}

Codeine has a relatively low BA (50\%), ${ }^{1}$ which is likely because of the extensive first-pass effect rather than poor absorption. Indeed, codeine's human fraction of dose absorbed $\left(F_{\text {abs }}\right)$ was reported to be high ( $>90 \%)$ based on cumulative urinary excretion of drug and drug-related material (chiefly codeine-6glucuronide), following oral administration. ${ }^{33-36}$ Although no studies with radiolabeled codeine could be found in the literature to support $F_{\text {abs }}$, the high-cumulative urinary excretion of drug and drug-related material is a very strong evidence for $F_{\text {abs }}$. Passive permeation is probably the main mechanism responsible for the absorption of codeine, as no information on transporter-mediated absorption of codeine could be found in the literature. Moreover, similar apical to basolateral $(a \rightarrow b)$ and basolateral to apical $(b \rightarrow a)$ permeability of codeine across Caco-2 cell monolayers was reported. ${ }^{35}$ As the involvement of transporters, either efflux or uptake, may result in an asymmetrical permeability, the similar $a \rightarrow b$ and $b \rightarrow a$ permeability suggests passive absorption, ${ }^{37,38}$ although it is recognized, theoretically at least, that trade-offs, for example, between simultaneous efflux and influx transporters, could balance each other. Similar absorption of oral and rectal dosage forms of codeine $^{39}$ also suggests passive permeability as the main absorptive mechanism, because the expression of transporters is very unlikely to be similar in the small intestine and in the colon. ${ }^{40}$ Neither dose linearity nor food effect studies for codeine phosphate are available in the literature.

\section{Permeability}

The permeability of codeine across Caco-2 cell monolayers was assessed by Skolnik et al. ${ }^{35}$ The apparent permeability $\left(P_{\text {app }}\right)$ of codeine was $2.29 \times 10^{-5} \mathrm{~cm} / \mathrm{s}$ in the $\mathrm{a} \rightarrow \mathrm{b}$ direction and $1.99 \times 10^{-5} \mathrm{~cm} / \mathrm{s}$ in the $\mathrm{b} \rightarrow \mathrm{a}$ direction. In comparison, the $P_{\text {app }}$ 
Table 2. Effective Permeability Values $\left(\mathrm{P}_{\text {eff }}, \times 10^{-5} \mathrm{~cm} / \mathrm{s}\right)$ Obtained for Codeine and Metoprolol After In Situ Single-Pass Perfusion to the Rat Proximal Jejunum at pH 6.5, Middle Small Intestine at pH 7.0, and to the Distal Ileum at $\mathrm{pH} 7.5$

\begin{tabular}{cccc}
\hline & $\begin{array}{c}\text { Proximal } \\
\text { Jejunum; } \\
\text { pH 6.5 }\end{array}$ & $\begin{array}{c}\text { Middle Small } \\
\text { Intestine; pH 7.0 }\end{array}$ & $\begin{array}{c}\text { Distal Ileum; } \\
\text { pH 7.5 }\end{array}$ \\
\hline Codeine & $3.5(0.7)$ & $7.8(1.9)$ & $13.1(1.1)$ \\
Metoprolol & $3.6(1.1)$ & $7.2(0.9)$ & $12.6(2.8)$ \\
\hline
\end{tabular}

Mean (SD); $n=6$ in each experimental group.

of metoprolol, the benchmark for low/high permeability class boundary, was $1.77 \times 10^{-5} \mathrm{~cm} / \mathrm{s}$ in the $\mathrm{a} \rightarrow \mathrm{b}$ direction and 9.28 $\times 10^{-6} \mathrm{~cm} / \mathrm{s}$ in the $\mathrm{b} \rightarrow$ a direction. For further comparison, values for the low-permeability drug cimetidine were 1.64 and 8.58 $\times 10^{-6} \mathrm{~cm} / \mathrm{s}$ in the absorptive and secretory directions. Thus, the permeability of codeine exceeds that of metoprolol, in the same laboratory, and codeine is therefore classified as a highpermeability drug according to this study. Furthermore, the similar permeability of codeine in both the absorptive and secretory directions indicates that the main mechanism of codeine absorption is passive permeation, with little or no involvement of transporters.

To further validate this result, we conducted in situ permeability studies of codeine phosphate versus metoprolol using the single-pass rat intestinal perfusion method.

The experimental procedure followed previous reports. ${ }^{18-20}$ Similar permeability was revealed for codeine and metoprolol throughout the entire small intestine; codeine and metoprolol permeability values were $3.5 \times 10^{-5}$ and $3.6 \times 10^{-5} \mathrm{~cm} / \mathrm{s}$ in the proximal jejunum, $7.8 \times 10^{-5}$ and $7.2 \times 10^{-5} \mathrm{~cm} / \mathrm{s}$ in the middle small intestine, and $1.3 \times 10^{-4}$ and $1.2 \times 10^{-4} \mathrm{~cm} / \mathrm{s}$ in the distal ileum, respectively (Table 2 ). These results corroborate the findings of Skolnik et al. ${ }^{35}$ and provide further evidence that codeine is a high-permeability drug.

\section{Distribution, Metabolism, and Elimination}

Codeine has a volume of distribution $\left(V_{\mathrm{d}}\right)$ of $3-7 \mathrm{~L} / \mathrm{kg}$ and is widely distributed throughout the body. ${ }^{34,41}$ Codeine is extensively metabolized by the liver, predominantly to codeine-6glucoronide, and in small part to norcodeine by CYP3A4.$^{34,42} \mathrm{~A}$ small fraction of codeine is converted by CYP2D6 to morphine, which is responsible for both the pharmacological activity and toxic effects of codeine. ${ }^{34,41-44}$ Only about $3 \%-5 \%$ of codeine dose is excreted unchanged in the urine. ${ }^{33,34,42}$ The elimination half-life of codeine was reported to be $1.8 \mathrm{~h} .{ }^{34}$ Quite variable clearance was reported in the literature, ranging from 40 to 140 L/h. ${ }^{34,42,44-48}$

\section{DOSAGE FORM PERFORMANCE}

\section{Excipients}

The excipients of several marketed IR solid oral drug products containing codeine phosphate as single API are given in Table 3. No specific studies about possible effects of these excipients on codeine release and absorption have been reported to date. Moreover, the products are marketed in ICH associated countries, and hence, one may assume that they have passed a rigorous $\mathrm{BE}$ study, indicating that the excipients, in the amounts used, do not interfere with codeine absorption.

\section{In Vivo BE}

No BE studies of drug products containing codeine as a single API were found in the literature. However, several IR combination drug products containing codeine phosphate have been demonstrated to be bioequivalent and the results are summarized in Table 4.

In an open, two treatment, two period crossover study in 24 subjects, a test product containing aspirin, butalbital, caffeine, and codeine $(325 / 50 / 40 / 30 \mathrm{mg}$ ) produced by Jerome Stevens was found to be bioequivalent to a reference product (Sandoz's Fiorinal); The dose used in the study consisted of two capsules from each product, bringing the total administered dose of codeine to $60 \mathrm{mg}$. The $90 \%$ confidence interval (CI) values of the test to reference (T/R) ratios for $\mathrm{AUC}_{0-t}, \mathrm{AUC}_{0-\infty}$, and $C_{\max }$ for codeine were $0.92-1.08,0.93-1.06$, and $0.99-1.14$, respectively (www.accessdata.fda.gov/drugsatfda_docs/anda/98/74951_Butalbital,\%20Aspirin,\%20Caffeine,\%20and\%20Codeine\% 20Phosphate_Bioeqr.pdf).

An additional two-way crossover BE study between a similar combination drug product (aspirin, butalbital, caffeine, and codeine; 325/50/40/30 mg) manufactured by Endo pharmaceuticals and the same reference formulation (Sandoz's Fiorinal) was performed in 24 subjects. Again, the total administered dose of codeine was $60 \mathrm{mg}$. The $90 \% \mathrm{CI}$ values of the test to reference (T/R) ratios for $\mathrm{AUC}_{0-t}, \mathrm{AUC}_{0-\infty}$, and $C_{\max }$ for codeine were $0.98-1.10,0.99-1.11$, and $0.95-1.14$, respectively (www.accessdata.fda.gov/drugsatfda_docs/nda/99/75351_Butalbital_bioeqr.pdf).

A randomized, single dose, open-labeled two-period crossover study compared a test formulation of ibuprofen and codeine (200/12.8 mg) produced by The Boots Company PLC (UK) to the reference formulation Nurofen Plus (Crookes Healthcare Limited, UK). The $90 \%$ CI values of the test to reference (T/R) ratios for $\mathrm{AUC}_{0-t}, \mathrm{AUC}_{0-\infty}$, and $C_{\max }$ for codeine were $0.91-1.00,0.91-1.00$, and 0.86-0.97, respectively (www. mhra.gov.uk/home/groups/par/documents/webysiteresources/ con103096.pdf).

It should be noted that the dissolution of the products described above follows the USP requirements, but does not meet the FDA biowaiver dissolution criterion.

\section{Dissolution}

In the first two aforementioned BE studies, a dissolution assay was performed under the conditions specified by the USP for capsules containing the combination aspirin, butalbital, caffeine, and codeine. The tests were run using USP apparatus 2 in $50 \mathrm{rpm}$ for $60 \mathrm{~min}$, with a medium of $1000 \mathrm{~mL}$ of water. In both studies, both the reference and the test products met the USP dissolution requirements of minimum $75 \%$ of the amount of active ingredients dissolved within $60 \mathrm{~min}$. The third BE study did not specify whether dissolution studies were conducted.

\section{DISCUSSION}

\section{Solubility}

Taking $60 \mathrm{mg}$ as the highest dose strength of codeine, the minimal solubility that would allow the "high solubility" classification is $0.24 \mathrm{mg} / \mathrm{mL}$. We found that the solubility of codeine 
Table 3. Excipients ${ }^{a}$ Present in Codeine Phosphate IR Solid Oral Drug Products ${ }^{b}$ with a Marketing Authorization (MA) in Canada (CA), Czech Republic (CZ), Germany (DE), Denmark (DK), Spain (ES), France (FR), Ireland (IE), The Netherlands (NL), Norway (NO), Romania (RO), Sweden (SE), Slovakia (SK), and United Kingdom (UK) ${ }^{c}$, and the Minimal and Maximal Amount of that Excipient Present per Dosage Unit in Solid Oral Drug Products with a MA in the US ${ }^{d}$

Excipient

Acacia

Calcium hydrogen phosphate

Cellulose, microcrystalline

Cellulose, powdered

Croscarmellose sodium

Crospovidone

Ethylcellulose

Gelatin

Hypromellose

Lactose

Magnesium stearate

Povidone

Propylene glycol

Silica

Sodium laurilsulfate

Sodium starch glycolate

Sodium metabisulfite

Sorbitol

Starch

Starch, pregelatinised

Stearic acid

Sucrose

Talc
Drug Products Containing That Excipient with

a MA Granted by the Named Country

$\mathrm{UK}(1)$

$\mathrm{ES}(2)$

$\mathrm{CA}(3,4), \mathrm{DK}(5,6), \mathrm{ES}(2), \mathrm{FR}(7), \mathrm{IS}(8), \mathrm{NL}(9), \mathrm{NO}(10), \mathrm{RO}(11)$, and $\mathrm{SE}(12)$

$\mathrm{DE}(13)$

$\mathrm{CA}(3)$

$\mathrm{DE}(14)$

$\mathrm{DE}(15)$

CZ(16), DE(15), DK(5,6,17), IS(8), NO(10), RO(18,19), SE(12), and $\mathrm{SK}(20)$

$\mathrm{DK}(6)$ and $\mathrm{NO}(10)$

$\mathrm{CA}(3,4), \mathrm{CZ}(16), \mathrm{DE}(13,14,21,22), \mathrm{DK}(5,6,17), \mathrm{IE}(23), \mathrm{IS}(8), \mathrm{NL}(9,24), \mathrm{NO}(10)$, $\mathrm{RO}(11,18,19,25-27), \mathrm{SE}(12), \mathrm{SK}(20)$, and $\mathrm{UK}(1,28)$

$\mathrm{CA}(3,4), \mathrm{CZ}(16), \mathrm{DE}(13-15,21), \mathrm{DK}(5,6,17), \mathrm{ES}(2), \mathrm{FR}(7), \mathrm{IE}(23), \operatorname{IS}(8), \mathrm{NL}(9,24)$, $\mathrm{NO}(10), \mathrm{RO}(11,18,19,25-27), \mathrm{SE}(12), \mathrm{SK}(20)$, and $\mathrm{UK}(1,28)$

$\mathrm{DE}(14,15)$ and $\mathrm{RO}(25,26)$

$\mathrm{DK}(6)$ and $\mathrm{NO}(10)$

$\mathrm{CA}(3,4), \mathrm{DE}(13,22), \mathrm{ES}(2), \mathrm{IE}(23), \mathrm{NL}(9)$, and $\mathrm{RO}(11,26)$

$\mathrm{DE}(15)$

$\mathrm{DE}(13)$ and $\mathrm{ES}(2)$

IS(8) and SE(12)

$\mathrm{DE}(13)$

CZ(16), DE(21,22), DK(5,6,17), IS(8), NL(9,24), NO(10) RO(11,18,19,25-27), SE(12), $\mathrm{SK}(20)$, and $\mathrm{UK}(1,28)$

$\mathrm{CA}(4), \mathrm{DE}(22)$, and $\mathrm{UK}(1,28)$

$\mathrm{DE}(15)$

CZ(16), DE(15,21), DK(5,6,17), ES(2), IS(8), NL(9), NO(10), RO(11,18,19,25-27), $\mathrm{SE}(12)$, and $\operatorname{SK}(20)$
Range Present in Solid Oral Dosage Forms with a MA in the US (mg)

$5-156$
$104-850$
$4.6-1385$
$44-170$
$2-180$
$4.4-792^{*}$
$1.0-121^{*}$
$1-756^{*}$
$0.8-537$
$23-1020^{*}$

$0.15-401^{*}$

$0.17-240$
$1.5-148$
$0.50-100$
$0.65-52$
$2-876^{*}$
$0.36-8$
$5-337$
$0.44-1135$
$4.2-600$
$0.9-72^{*}$
$12-900$
$0.1-220^{*}$

${ }^{a}$ Colourants, water, and ingredients present in the coating are not included. Substances are excluded if it can be assumed that the constituents are only present in the coating/polish.

${ }^{b}$ Excluded are: combination products.

${ }^{c}$ Sources of data: CA, www.hc-sc.gc.ca (accessed 28-01-2014); CZ, www.sukl.cz/ (accessed 28-01-2014); DE, www.rote-liste.de; (accessed 29-01-2014); DK, www.dkma.dk (accessed 29-01-2014); ES, www.aemps.es (accessed 29-01-2014); FR, www.theriaque.org/; (accessed 29-01-2014); IE, www.imb.ie/ (accessed 04-02-2014); IS, www.serlyfjaskra.is (accessed 04-02-2014) NL, www.cbg-meb.nl. (accessed 05-02-2014); NO, www.legemiddelverket.no/ (accessed 05-02-2014); RO, www.anm.ro/ (accessed 05-02-2014); SE, www.lakemedelsverket.se (accessed 05-02-2014); SK, www.sukl.sk (accessed 05-02-2014); UK, www.medicines.org.uk/emc/ (accessed 1002-2014).

${ }^{d}$ US: FDA's Inactive Ingredient Database, http://www.fda.gov/Drugs/InformationOnDrugs/ucm113978.htm (version date: September 16, 2013).

"The upper range value reported is unusually high for solid oral dosage forms and the authors doubt its correctness.

1. Codeine phosphate $15 /-30 /-60 \mathrm{mg}$ tablets (Wockhardt UK Ltd.).

2. Codeisan $28.7 \mathrm{mg}$ comprimidos.

3. CODEINE 15/-30 (codeine phosphate tablets, USP 15/-30 mg) (LABORATOIRES TRIANON INC.)

4. ${ }^{\mathrm{N}}$ ratio-CODEINE (codeine phosphate tablets USP $15 /-30 \mathrm{mg}$ ) (Teva Canada Limited).

5. "Kodein" "Alternova," filmovertrukne tabletter.

6. Kodein "DAK," filmovertrukne tabletter.

7. PADERYL $19.5 \mathrm{mg}$ CPR.

8. Kodein Recip $25 \mathrm{mg}$ töflur.

9. Codeïnefosfaat $10 /-15 /-20 \mathrm{PCH}$, tabletten $10 /-15 /-20 \mathrm{mg}$.

10. Kodein $25 \mathrm{mg}$ tabletter.

11. CODEINĂ FOSFORICĂ.

12. Kodein Recip $25 \mathrm{mg}$ tabletter.

13. Codeinum phosphoricum Berlin-Chemie tabletten.

14. codi $\mathrm{OPT}^{\mathfrak{B}}$ tabletten.

15. Tussoret ${ }^{\text {BS }}$ Tag-/Nacht-Kapseln.

16. Codein Slovakofarma $15 /-30 \mathrm{mg}$.

17. Kodein "SAD," tabletter.

18. Codeină Fabiol $15 \mathrm{mg}$, comprimate.

19. FOSFAT DE CODEINA $15 \mathrm{mg}$ comprimate.

20. Codein-SLOVAKOFARMA $15 /-30 \mathrm{mg}$.

21. Codeinum phosphoricum Compren ${ }^{\circledR} 30 \mathrm{mg} /$-forte Compren ${ }^{\circledR} 50 \mathrm{mg}$ tabletten.

22. Codipertussin mite tabletten codeinum phosphate $30 \mathrm{mg} /$ codipertussin tabletten codeinum phosphate $50 \mathrm{mg}$

23. Codant $30 \mathrm{mg}$ tablets.

24. Codeïnefosfaat ratiopharm $10 /-20 \mathrm{mg}$, tabletten.

25. CODEINĂ FOSFAT $15 \mathrm{mg}$ comprimate.

26. CODEINĂ FOSFAT LPH $15 \mathrm{mg}$ comprimate.

27. CODEINĂ FOSFAT MCC $15 \mathrm{mg}$ comprimate.

28. CODEINE PHOSPHATE TABLETS BP $15 /-30 /-60 \mathrm{mg}$ (Actavis UK Limited). 


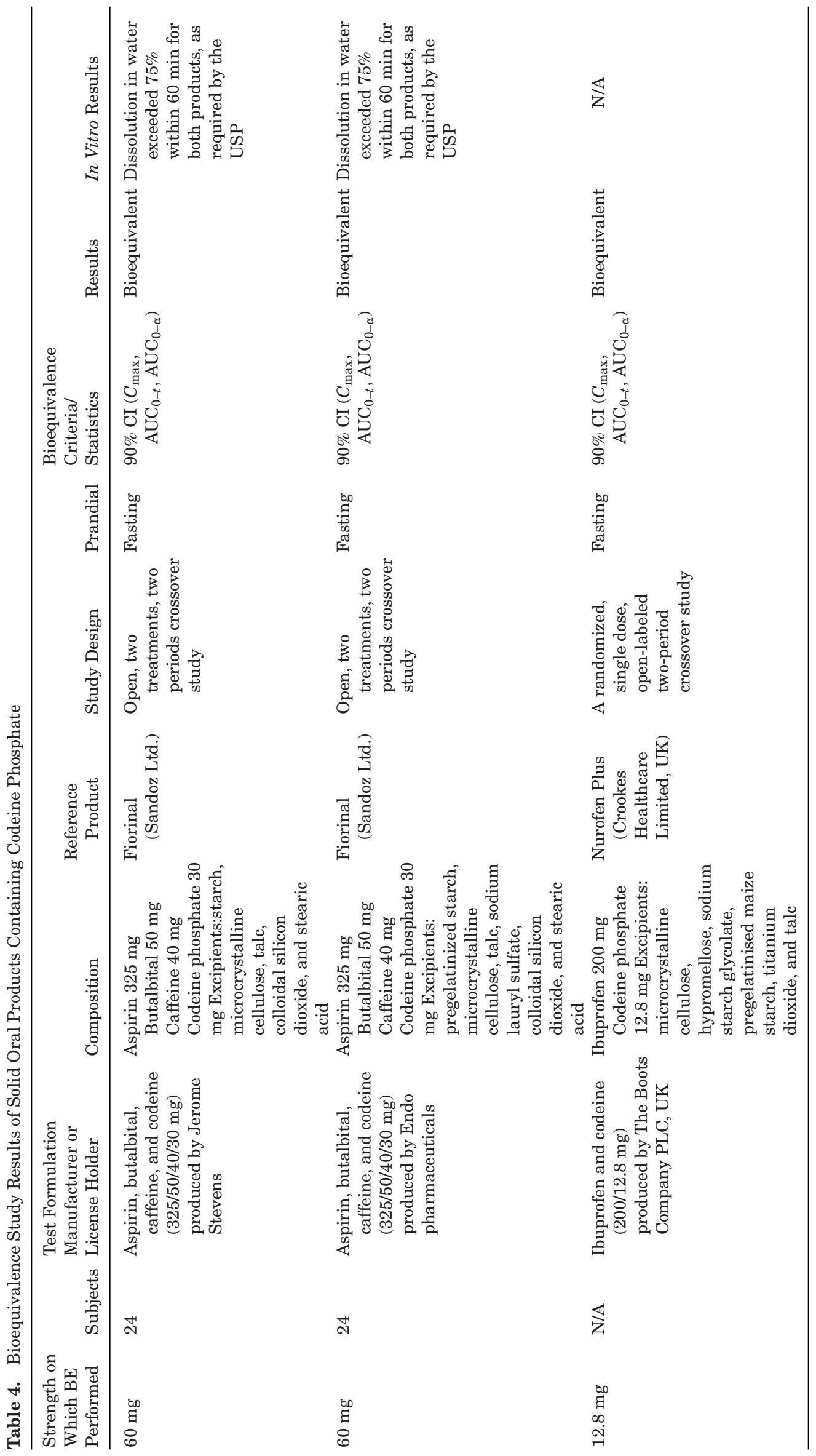


exceeded $120 \mathrm{mg} / \mathrm{mL}$ throughout the $\mathrm{pH}$ range of $1-7.5$, which means that the $D_{0}$ of codeine is lower than 0.002 , unequivocally indicating a BCS high-solubility classification.

\section{Permeability and Absorption}

Codeine has a human intestinal absorption of more than $90 \%$ based on cumulative urinary excretion of drug and drug-related material (chiefly codeine-6-glucuronide) following oral administration. ${ }^{33-36}$

Codeine was previously classified as high-permeability drug in Caco-2 monolayers study. ${ }^{35}$ This result was further strengthened by our rat perfusion study in three different segments throughout the small intestine, which showed that the permeability of codeine is similar to the reference drug metoprolol throughout the entire small intestine. Taken together, these results indicate that codeine may be safely classified as a highpermeability drug.

\section{BCS and BDDCS Classification}

Previously, Skolnik et al. ${ }^{35}$ classified codeine as a BCS class 1 drug based on its high permeability across Caco- 2 monolayers. Additional publications also classified codeine as a BCS class 1 compound. ${ }^{17,36,49-51}$

On the contrary, Kasim et al. ${ }^{52}$ and Takagi et al. ${ }^{53}$ used partition coefficient values for the classification of drug permeability, and because codeine's $\log P(1.1)$ value is lower than that of the reference drug metoprolol (2.3), ${ }^{23}$ they provisionally classified codeine phosphate as a BCS class 3 drug. In general, a reasonable correlation exists between $\log P$ values and jejunal permeability; however, a significant number of false-negative cases have been recorded, in which drugs with lower $\log P$ than metoprolol exhibit complete absorption. These include antipyrine, cephalexin, D-glucose, levodopa, L-leucine, phenylalanine, piroxicam, valacyclovir, ${ }^{52,53}$ pseudoephedrine, ${ }^{23}$ and sotalol, $^{22}$ indicating the difficulty of assigning BCS classification based merely on limited physicochemical characteristics.

On the basis of the urinary recovery data in humans, the work of Skolnik et al., ${ }^{35}$ and the experimental data presented in this monograph, it can be concluded that codeine phosphate can be safely classified as a BCS class 1 drug. Benet et al. ${ }^{54}$ classified codeine as a class 1 compound according to the Biopharmaceutics Drug Disposition Classification System (BDDCS) because of its high fraction of dose metabolized.

\section{Risks of Bioinequivalence Caused by Excipients and/or Manufacturing Parameters}

No information was found in the literature concerning potential influence of excipients or manufacturing process on the performance of codeine formulations.

\section{Patient's Risks Associated with Bioinequivalence}

The main risk associated with bioinequivalence of generic codeine formulations is codeine toxicity (i.e., CNS and respiratory depression) that is related to the conversion of codeine to morphine and is highly dependent on the CYP2D6 phenotype. The fraction of codeine dose converted to morphine is 5\%-10\% in $\mathrm{EM}^{42}$; however, the amount of codeine converted to morphine may be higher in UM by as much as 80 -fold compared with EM. ${ }^{10,15}$ For this reason, the CPIC Guidelines advise against the use of codeine in patients that were found to be UM by genetic screening. ${ }^{11}$ This complication, however, is present irrespective of the dosage form, and hence is unrelated to $\mathrm{BE}$ considerations.

It should also be noted that codeine has long been recognized as a drug of abuse, and despite this, it is incorporated in many OTC drug products. Again, the potential for abuse is irrespective of the dosage form, and hence should not be regarded as to BE considerations.

\section{CONCLUSIONS}

Codeine phosphate is a high-solubility, high-permeability drug, and is therefore classified as a BCS class 1 compound. The risk of bioinequivalence is manageable as long as the use of codeine is avoided in UM. For these reasons, we consider codeine phosphate to be a good candidate for waiver of in vivo BE studies.

Granting a biowaiver for IR solid oral dosage forms containing codeine phosphate is scientifically justified, subjected to the following conditions: (1) the test product contains only excipients that are well known and used in normal amounts, for example, those tabulated for products with MA in ICH-associated countries (Table 3); and (2) both the test and comparator dosage forms enable very rapid dissolution of codeine, or, rapid dissolution with similarity of the dissolution profiles demonstrated at least at $\mathrm{pH} 1.2,4.5$, and 6.8 for codeine. For products containing other API(s) in addition to codeine, the possibility of a biowaiver for each API should be separately considered.

\section{ACKNOWLEDGMENTS}

This biowaiver monograph is part of a project of the FIP, Focus Group BCS and Biowaiver, www.fip.org/bcs. This article reflects the scientific opinion of the authors and not necessarily the policies of the regulating agencies: the FIP, RIVM, ANVISA, or the World Health Organization (WHO).

\section{REFERENCES}

1. Goodman L, Gilman A. 2006. The pharmacological basis of therapeutics. 11th ed. New York: The Macmillian Company.

2. Aylward M, Maddock J, Davies DE, Protheroe DA, Leideman T. 1984. Dextromethorphan and codeine: Comparison of plasma kinetics and antitussive effects. Eur J Respir Dis 65(4):283-291.

3. Freestone C, Eccles R. 1997. Assessment of the antitussive efficacy of codeine in cough associated with common cold. J Pharm Pharmacol 49(10):1045-1049.

4. Hutchings HA, Eccles R. 1994. The opioid agonist codeine and antagonist naltrexone do not affect voluntary suppression of capsaicin induced cough in healthy subjects. Eur Respir J 7(4):715-719.

5. Bolser DC. 2006. Cough suppressant and pharmacologic protussive therapy: ACCP evidence-based clinical practice guidelines. Chest 129(1 Suppl):238S-249S

6. Mignat C, Wille U, Ziegler A. 1995. Affinity profiles of morphine, codeine, dihydrocodeine and their glucuronides at opioid receptor subtypes. Life Sci 56(10):793-799.

7. Volpe DA, McMahon Tobin GA, Mellon RD, Katki AG, Parker RJ, Colatsky T, Kropp TJ, Verbois SL. 2011. Uniform assessment and ranking of opioid mu receptor binding constants for selected opioid drugs. Regul Toxicol Pharmacol 59(3):385-390.

8. Chau TT, Harris LS. 1980. Comparative studies of the pharmacological effects of the d- and l-isomers of codeine. J Pharmacol Exp Ther 215(3):668-672. 
9. Kahan M, Mailis-Gagnon A, Wilson L, Srivastava A. 2011. Canadian guideline for safe and effective use of opioids for chronic noncancer pain: Clinical summary for family physicians. Part 1: General population. Can Fam Physician 57(11):1257-1266, e407-e418.

10. Gasche Y, Daali Y, Fathi M, Chiappe A, Cottini S, Dayer P, Desmeules J. 2004. Codeine intoxication associated with ultrarapid CYP2D6 metabolism. N Engl J Med 351(27):2827-2831.

11. Crews KR, Gaedigk A, Dunnenberger HM, Klein TE, Shen DD, Callaghan JT, Kharasch ED, Skaar TC. 2012. Clinical Pharmacogenetics Implementation Consortium (CPIC) guidelines for codeine therapy in the context of cytochrome P450 2D6 (CYP2D6) genotype. Clin Pharmacol Ther 91(2):321-326.

12. Kelly LE, Madadi P. 2012. Is there a role for therapeutic drug monitoring with codeine? Ther Drug Monit 34(3):249-256.

13. Leppert W. 2011. CYP2D6 in the metabolism of opioids for mild to moderate pain. Pharmacology 87(5-6):274-285.

14. Kelly LE, Rieder M, van den Anker J, Malkin B, Ross C, Neely MN, Carleton B, Hayden MR, Madadi P, Koren G. 2012. More codeine fatalities after tonsillectomy in North American children. Pediatrics 129(5):e1343-e1347.

15. Ciszkowski C, Madadi P, Phillips MS, Lauwers AE, Koren G. 2009. Codeine, ultrarapid-metabolism genotype, and postoperative death. $\mathrm{N}$ Engl J Med 361(8):827-828.

16. Brousseau DC, McCarver DG, Drendel AL, Divakaran K, Panepinto JA. 2007. The effect of CYP2D6 polymorphisms on the response to pain treatment for pediatric sickle cell pain crisis. J Pediatr 150(6):623626.

17. Zur M, Hanson AS, Dahan A. 2014. The complexity of intestinal permeability: Assigning the correct BCS classification through careful data interpretation. Eur J Pharm Sci. [Epub ahead of print]

18. Dahan A, Amidon GL. 2009. Small intestinal efflux mediated by MRP2 and BCRP shifts sulfasalazine intestinal permeability from high to low, enabling its colonic targeting. Am J Physiol Gastrointest Liver Physiol 297(2):G371-G377.

19. Dahan A, Amidon GL. 2009. Grapefruit juice and its constituents augment colchicine intestinal absorption: Potential hazardous interaction and the role of p-glycoprotein. Pharm Res 26(4):883-892.

20. Dahan A, Amidon GL. 2009. Segmental dependent transport of low permeability compounds along the small intestine due to $\mathrm{P}$ glycoprotein: The role of efflux transport in the oral absorption of BCS class III drugs. Mol Pharm 6(1):19-28.

21. Dahan A, Lennernäs H, Amidon GL. 2012. The fraction dose absorbed, in humans, and high jejunal human permeability relationship. Mol Pharm 9(6):1847-1851.

22. Dahan A, Miller JM, Hilfinger JM, Yamashita S, Yu LX, Lennernäs H, Amidon GL. 2010. High-permeability criterion for BCS classification: Segmental/pH dependent permeability considerations. Mol Pharm 7(5):1827-1834

23. Fairstein M, Swissa R, Dahan A. 2013. Regional-dependent intestinal permeability and BCS classification: Elucidation of pH-related complexity in rats using pseudoephedrine. AAPS J 15(2):589-597.

24. Zur M, Gasparini M, Wolk O, Amidon GL, Dahan A. 2014. The low/high BCS permeability class boundary: Physicochemical comparison of metoprolol and labetalol. Mol Pharmaceutics. [Epub ahead of print]

25. Beig A, Miller JM, Dahan A. 2012. Accounting for the solubilitypermeability interplay in oral formulation development for poor water solubility drugs: the effect of PEG-400 on carbamazepine absorption. European Journal of Pharmaceutics and Biopharmaceutics 81(2) 38691.

26. Dahan A, Amidon GL. 2010. MRP2 mediated drug-drug interaction: indomethacin increases sulfasalazine absorption in the small intestine, potentially decreasing its colonic targeting. International Journal of Pharmaceutics 386(1-2) 216-20.

27. Beig A, Agbaria R, Dahan A. 2013. Oral delivery of lipophilic drugs: The tradeoff between solubility increase and permeability decrease when using cyclodextrin-based formulations. PLoS ONE 8(7): e68237.
28. Dahan A, Beig A, Ioffe-Dahan V, Agbaria R, Miller J. 2013. The twofold advantage of the amorphous form as an oral drug delivery practice for lipophilic compounds: Increased apparent solubility and drug flux through the intestinal membrane. AAPS J 15(2):347353.

29. Miller JM, Beig A, Carr RA, Webster GK, Dahan A. 2012. The solubility-permeability interplay when using cosolvents for solubilization: Revising the way we use solubility-enabling formulations. Mol Pharm 9(3):581-590.

30. CDER/FDA. 2000. Guidance for industry: Waiver of in vivo bioavailability and bioequivalence studies for immediate-release solid oral dosage forms based on a biopharmaceutics classification system.

31. Meylan WM, Howard PH. 1995. Atom/fragment contribution method for estimating octanol-water partition coefficients. J Pharm Sci 84(1):83-92.

32. Fuguet E, Reta M, Gibert C, Roses M, Bosch E, Rafols C. 2008. Critical evaluation of buffering solutions for $\mathrm{pKa}$ determination by capillary electrophoresis. Electrophoresis 29(13):2841-2851.

33. Bodd E, Beylich KM, Christophersen AS, Morland J. 1987. Oral administration of codeine in the presence of ethanol: A pharmacokinetic study in man. Pharmacol Toxicol 61(5):297-300.

34. Vree TB, Verwey-van Wissen CP. 1992. Pharmacokinetics and metabolism of codeine in humans. Biopharm Drug Dispos 13(6):445460.

35. Skolnik S, Lin X, Wang J, Chen XH, He T, Zhang B. 2010. Towards prediction of in vivo intestinal absorption using a 96 -well Caco-2 assay. J Pharm Sci 99(7):3246-3265.

36. Yalkowsky SH, Johnson JL, Sanghvi T, Machatha SG. 2006. A 'rule of unity' for human intestinal absorption. Pharm Res 23(10):24752481.

37. Dahan A, Sabit H, Amidon GL. 2009. Multiple efflux pumps are involved in the transepithelial transport of colchicine: Combined effect of P-gp and MRP2 leads to decreased intestinal absorption throughout the entire small intestine. Drug Metab Dispos 37(10):20282036.

38. Hubatsch I, Ragnarsson EGE, Artursson P. 2007. Determination of drug permeability and prediction of drug absorption in Caco-2 monolayers. Nat Protoc 2(9):2111-2119.

39. Moolenaar F, Grasmeijer G, Visser J, Meijer DK. 1983. Rectal versus oral absorption of codeine phosphate in man. Biopharm Drug Dispos 4(2):195-199.

40. Cao X, Gibbs S, Fang L, Miller H, Landowski C, Shin H-C, Lennernas H, Zhong Y, Amidon G, Yu L, Sun D. 2006. Why is it challenging to predict intestinal drug absorption and oral bioavailability in human using rat model. Pharm Res 23(8):1675-1686.

41. Quiding H, Anderson P, Bondesson U, Boréus LO, Hynning PÅ. 1986. Plasma concentrations of codeine and its metabolite, morphine, after single and repeated oral administration. Eur J Clin Pharm 30(6):673-677.

42. Yue QY, Hasselstrom J, Svensson JO, Sawe J. 1991. Pharmacokinetics of codeine and its metabolites in Caucasian healthy volunteers: Comparisons between extensive and poor hydroxylators of debrisoquine. Br J Clin Pharmacol 31(6):635-642.

43. Somogyi AA, Barratt DT, Coller JK. 2007. Pharmacogenetics of opioids. Clin Pharmacol Ther 81(3):429-444.

44. Ammon S, Marx C, Behrens C, Hofmann U, Murdter T, Griese E-U, Mikus G. 2002. Diclofenac does not interact with codeine metabolism in vivo: A study in healthy volunteers. BMC Clin Pharmacol 2 (1):2.

45. Caraco Y, Sheller J, Wood AJJ. 1999. Impact of ethnic origin and quinidine coadministration on codeine's disposition and pharmacodynamic effects. J Pharmacol Exp Ther 290(1):413-422.

46. Gil Berglund E, Johannsson G, Beck O, Bengtsson BÅ, Rane A. 2002. Growth hormone replacement therapy induces codeine clearance. Eur J Clin Invest 32(7):507-512.

47. Mohammed SS, Ayass M, Mehta P, Kedar A, Gross S, Derendorf H. 1993. Codeine disposition in sickle cell patients compared with healthy volunteers. J Clin Pharmacol 33(9):811-815. 
48. Rogers JF, Findlay JWA, Hull JH, Butz RF, Jones EC, Bustrack JA, Welch RM. 1982. Codeine disposition in smokers and nonsmokers. Clin Pharm Ther 32(2):218-227.

49. Dahan A, Wolk O, Kim YH, Ramachandran C, Crippen GM, Takagi T, Bermejo M, Amidon GL. 2013. Purely in silico BCS classification: Science based quality standards for the world's drugs. Mol Pharm 10(11):4378-4390.

50. Pham-The H, Garrigues T, Bermejo M, González-Álvarez I,Monteagudo MC, Cabrera-Pérez MÁ. 2013. Provisional classification and in silico study of biopharmaceutical system based on Caco-2 cell permeability and dose number. Mol Pharm 10(6):24452461.

51. Zhao YH, Le J, Abraham MH, Hersey A, Eddershaw PJ, Luscombe CN, Boutina D, Beck G, Sherborne B, Cooper I, Platts JA. 2001.
Evaluation of human intestinal absorption data and subsequent derivation of a quantitative structure-activity relationship (QSAR) with the Abraham descriptors. J Pharm Sci 90(6):749-784.

52. Kasim NA, Whitehouse M, Ramachandran C, Bermejo M, Lennernas H, Hussain AS, Junginger HE, Stavchansky SA, Midha KK, Shah VP, Amidon GL. 2004. Molecular properties of WHO essential drugs and provisional biopharmaceutical classification. Mol Pharm 1(1):8596.

53. Takagi T, Ramachandran C, Bermejo M, Yamashita S, Yu LX, Amidon GL. 2006. A provisional biopharmaceutical classification of the top 200 oral drug products in the United States, Great Britain, Spain, and Japan. Mol Pharm 3(6):631-643.

54. Benet LZ, Broccatelli F, Oprea TI. 2011. BDDCS applied to over 900 drugs. AAPS J 13(4):519-547. 